\title{
A Dinâmica entre Liderança e Identificação: Sobre a Influência Consentida nas Organizações Contemporâneas
}

\author{
Eduardo Davel \\ Hilka Vier Machado
}

\section{Resumo}

O conjunto de transformações estruturais, sociais e culturais pelas quais as organizações contemporâneas vêm passando sugere uma nova dinâmica no exercício da influência e uma renovação nas formas de conceber e analisar tal exercício. Este artigo explora as sutilezas dessa dinâmica, desenvolvendo um esquema teórico que considera os fenômenos de liderança e de identificação em sua complementaridade. A influência do líder se explica pelo ordenamento significativo da realidade das pessoas que, simultaneamente, se identificam e consentem em tal influência. Ambos os fenômenos de liderança e identificação mobilizam e articulam poder, mas também recursos cognitivos e emocionais. Este esquema conceitual permite então uma avaliação mais acurada e atual da liderança como processo dinâmico que envolve: (1) não só questões políticas, mas também cognitivas e emocionais; (2) não só ordenamento, mas também reconhecimento e consentimento.

Palavras-chaves: liderança; identificação; consentimento; cognição; emoção.

\begin{abstract}
The structural, social, and cultural composite of transformations which contemporary organizations are facing indicates a new dynamic in exercising leadership and a renewal in the way of conceiving and analyzing that exercise. This paper explores the sensitiveness of that dynamic developing a conceptual framework that considers leadership and identification as complementary phenomena. Leaders' influence emerges from the significant ordering of reality of people that, simultaneously, identify themselves with and consent on that influence. Both phenomena mobilize and articulate power, cognition, and emotion resources. That conceptual framework allows us to make a more accurate and up-to-date evaluation of leadership as a dynamic process that involves: (1) political as well as cognitive, and emotional issues; and (2) ordering as well as recognizing, and consenting processes.
\end{abstract}

Key words: leadership; identification; consenting; cognition; emotion. 


\section{INTRODUÇÃO}

A liderança, como campo teórico e empírico de pesquisa, tem-se desenvolvido de maneira variada, dependendo das concepções e preferências metodológicas adotadas pelos pesquisadores. Talvez o aspecto mais controverso deste campo de pesquisa se refira aos diferentes (e em parte contraditórios) fundamentos epistemológicos que recortam e embasam os estudos sobre liderança (Hunt et al., 1988). Na sua globalidade, essas distinções são marcadas pelos focos de análise utilizados, que privilegiam segmentadamente os traços do líder, o seu comportamento, os aspectos relacionados ao poder e à influência ou os fatores situacionais (Yukl, 1989; Aubert, 1991; Yukl e Van Fleet, 1992). Para alguns, dentro desta segmentação de análises, a liderança transformacional e carismática assunto popular na década de 80 - se torna uma abordagem híbrida que envolveria elementos de diversas abordagens (Yukl, 1989; Yukl e Van Fleet, 1992), mas que não daria conta de articular e atualizar o prisma vasto e às vezes divergente de abordagens teóricas.

Abordagens mais recentes sobre a liderança enfatizam a necessidade de aprofundar o conhecimento dessa problemática, considerando-a como um relacionamento, uma reciprocidade entre líder e seguidores nos planos social, simbólico, identitário e cultural. Compreender o processo de liderança em tais planos teóricos torna-se cada vez mais crucial para atualizá-lo em face das transformações drásticas pelas quais vêm passando a administração e a vida nas organizações. Os novos contextos organizacionais têm primado pela flexibilidade e pela cooperação e tendem, conseqüentemente, a enaltecer a figura do líder, realocando as responsabilidades do chefe com as ambigüidades do coach (Sennett, 1998). Por exemplo, nas empresas estruturadas no trabalho em equipe, onde as práticas internas são guiadas pelas mudanças cambiantes no ambiente externo, os líderes se tornam figuras estrategicamente importantes. As responsabilidades tradicionalmente conferidas aos cargos de chefia e supervisão agora se encontram difusas no âmbito da equipe de trabalho (Davel, Rolland e Tremblay, 2000) e no âmbito de um processo de produção mais flexível.

Este artigo contextualiza os processos de liderança nesse ambiente de transformações organizacionais contemporâneas; explora, então, seus aspectos processuais, relacionais e psicossociais; e propõe um esquema conceitual que relaciona o processo de liderança ao de identificação, enfatizando suas dimensões políticas, cognitivas e emocionais. Fazem parte da simbiose entre liderança 
e identificação os processos de ordenamento e de consentimento. De fato, em um contexto organizacional contemporâneo regido pela abundância das imagens (Alvesson, 1990) e por reestruturações radicais (Hirschhorn, 1997), o processo de liderança se torna cada vez mais processual e circunstancial, datado no tempo e dependente do reconhecimento e do consentimento que alcançará nas pessoas. À medida que as organizações contemporâneas se tornam mais vulneráveis ao mercado em que atuam, líderes e seguidores tendem a se tornar mais vulneráveis ao exercício da influência de ambas as partes (Hirschhorn, 1997).

Neste contexto de acontecimentos e mudanças, o foco de atenção nos líderes enquanto pessoas tende a se deslocar para a liderança como um fenômeno processual (Hosking, 1988; Hosking e Fineman, 1990), em que atos organizadores de influência contribuem para o ordenamento das interações e relações, atividades e sentimentos das pessoas. Trata-se de um processo pelo qual as definições da realidade social são constantemente negociadas, aceitas, implementadas e renegociadas, promovendo-se e mobilizando-se valores, conhecimentos, sentimentos e interesses. Antes de aprofundar essa abordagem da liderança que integra, de forma dinâmica, os processos de identificação, abordaremos os processos de liderança e de identificação separadamente. Por fim, discutiremos as implicações que o modelo conceitual proposto neste artigo acarreta para a teoria e prática organizacional.

\section{O Fenómeno da Liderança nas Organizações}

A liderança nas organizações como fenômeno social complexo foi freqüente e tradicionalmente conceitualizada em termos de traços de personalidade, estilos de comportamento e fatores contingenciais (Yukl, 1989; Aubert, 1991; Yukl e Van Fleet, 1992; Bergamini, 1994; Northouse, 1997). Uma das teorias pioneiras a teoria dos traços - predominou até a década de 40, enfatizando especialmente as qualidades pessoais do líder. Logo em seguida, no início da década de 50, os cientistas comportamentais passaram a se preocupar com os aspectos que caracterizam o estilo de comportamento do líder. Os pesquisadores dirigem então sua atenção para aquilo que o líder faz, mostrando-se particularmente interessados nos tipos de comportamento por ele adotados, que seriam responsáveis pelo aumento da sua eficácia ao dirigir seus seguidores. Entre a década de 60 e o início da década de 80 , os enfoques situacionais ou contingenciais apontam o fato de que a emergência e a manutenção de um líder eficaz devem considerar aspectos que fazem parte do ambiente dentro do qual o líder está agindo. As teorias contingenciais ou situacionais exploram então as variáveis que cercam o proces- 
so de liderança, sem deixar de lado os diferentes tipos de comportamento dos líderes.

No seu conjunto, as pesquisas sobre traços, habilidades, motivos e estilos de liderança consolidam o campo teórico sobre liderança, enfatizando sobretudo três aspectos (Bryman, 1996): (1) o processo de influência pelo qual o líder tem um impacto sobre os outros, induzindo-os a se comportarem de uma determinada maneira; (2) este processo de influência é concebido como incorporado ao contexto de um grupo; e (3) o líder influencia o comportamento dos membros de um grupo rumo aos objetivos que o grupo pretende alcançar. A este corpo conceitual se vão acrescentando, ao longo da década de 80 e 90, as questões culturais e identificatórias ${ }^{(1)}$ que levam a liderança a ser definida como "influência nos objetivos e estratégias, influência no comprometimento e consentimento com relação aos comportamentos necessários para alcançar estes objetivos, influência na manutenção e identificação do grupo, e influência na cultura de uma organização" (Yukl, 1989, p. 253).

Nessas novas abordagens, a liderança é concebida como ação simbólica (Pfeffer, 1981) em que o líder se torna administrador do sentido (Smircich e Morgan, 1982), identificando para os liderados um sentido do que é importante e definindo a realidade organizacional para outros. Atrelada aos teóricos institucionalistas (Selznick, 1957; Biggart e Hamilton, 1987) e aos estudiosos do simbolismo organizacional (Pfeffer, 1981; Smircich e Morgan, 1982; Trice e Beyer, 1989), a liderança vai sendo concebida como a atividade central dos atores organizacionais, tal como eles desenvolvem, modelam e negociam os conteúdos dos esquemas interpretativos que definem as situações cotidianas de trabalho. Essa atividade processual envolve um tipo de ação social integradora (Alvesson, 1992, 1995a), em que a criação de certa "ilusão do controle" depende do desempenho simbólico do líder (Czarniawska-Joerges e Wolff, 1991).

Para Smircich e Morgan (1982), indivíduos em grupo atribuem influência àqueles membros que estruturam a experiência de maneira significativa. Certos indivíduos, como resultado de uma inclinação pessoal ou de resposta à expectativa de outros, se encontram exercendo influência, em virtude da função que desempenham na definição e ordenamento de situações. Eles emergem como líderes por causa do seu papel substantivo de enquadramento significativo das situações. Nessa perspectiva, fica claro que liderar é ser capaz de administrar e ordenar os significados que as pessoas dão àquilo que estão fazendo. Assim, o líder, considerado como ponto de ligação entre cada indivíduo e seu próprio mundo de trabalho, tem forte influência, quando se trata de favorecer ou comprometer a organização da estrutura interior daqueles que esperam dele um tipo de ação que possa, de alguma forma, organizar o mundo que os cerca (Bergamini, 1994). A eficácia do 
líder repousa na sua habilidade de tornar uma atividade significativa para aqueles que estão nesse conjunto de papéis - não de mudar comportamentos, mas de dar aos outros o senso de compreensão daquilo que estão fazendo (Smith e Peterson, 1989).

De forma geral, vários autores têm apontado a necessidade de uma reorientação radical no desenvolvimento teórico sobre a liderança, integrando as abordagens qualitativas que a vislumbrem como processo psicossocial definido pela interação humana (Smircich e Morgan, 1982; Hosking, 1988; Knights e Willmott, 1992; Alvesson, 1992, 1995b; Bryman, 1996). Alvesson (1992), no estudo empírico de uma empresa de consultoria no ramo de computação, avalia a liderança como ação social integradora, subordinada ao contexto cultural no qual se desenrola. Hosking (1988), por sua vez, conceitua liderança em termos de uma atividade processual organizadora (organizing), que inclui dimensões sociais, políticas, cognitivas e emocionais (Hosking e Fineman, 1990), enquanto Knights e Willmott (1992) articulam um modelo conceitual que focaliza o poder e a subjetividade como componentes fundamentais da prática social de liderar e de ordenar significativamente a realidade.

De todas essas abordagens podemos concluir que a liderança é, sobretudo, um relacionamento, um processo mútuo de ligação entre líder e seguidor. Tal processo envolve um relacionamento de influência em duplo sentido, orientado principalmente para o atendimento de objetivos e expectativas mútuas. Nesses termos, não poderíamos dizer que a liderança fica somente a cargo do líder. O processo de influência não está unicamente assegurado pela vontade do líder, mas sobretudo pela conjunção desta vontade com as imagens, desejos e crenças compartilhados pelo grupo. Não é o líder que ilustra a relação, mas é a relação que ilumina o líder (Baudrillard e Guillaume, 1994), requerendo esforços de cooperação, consentimento e reconhecimento por parte da coletividade (Hollander, 1978). Assim, o poder do líder depende desta congruência e está atrelado à ressonância que se estabelece entre a problemática pessoal do líder e as necessidades do grupo que se reconhece naquele (Aubert, 1991) durante o processo de identificação que se desenrola entre ambas as partes - líderes e liderados. A habilidade de ordenamento significativo da realidade e suas ressonâncias no imaginário coletivo é o que constitui a força do líder e fundamenta o exercício legítimo da sua influência; por isso, para avançarmos na compreensão das sutilezas da liderança como processo de ordenamento significativo da realidade, torna-se necessário integrar e aprofundar o entendimento do conceito de identificação. 


\section{O Processo de Identificação nas Organizaçóes}

Identificar é reconhecer (eu sou), é demonstrar afinidade, atração, de que resulta um processo de internalização (eu acredito) e de incorporação de crenças, valores, atitudes, num processo de emulação (Ashforth e Mael, 1989). Em outras palavras, o eu vai sendo moldado pelas interações vividas; e a identificação vai ocorrendo quando a crença das pessoas no líder se torna auto-referenciada e autodefinida, quando um indivíduo integra crenças sobre o líder em sua própria identidade por via da afinidade ou da emulação (Pratt, 1998). "Nas identificações adquiridas o outro entra na composição do si mesmo. [...] A identidade é feita dessas identificações com valores, normas, ideais, modelos e heróis, nos quais a pessoa e a comunidade se reconhecem. O reconhecer-se no contribui para o reconhecer-se com" (Ricoeur, 1990, p. 147).

A identificação é central na maneira como nos relacionamos com os líderes. É um processo vital para o estabelecimento de vínculos sociais entre os indivíduos, à medida que eles se reconhecem em suas disputas, expectativas e sofrimentos (Yiannis, 1999). Resumidamente, podemos dizer que o processo de identificação social se constitui (1) pela definição dos indivíduos em termos de filiação a uma mesma categoria social (categorização); (2) pela distinção, prestígio e saliência dos valores e práticas do grupo em relação a outros grupos comparáveis (Oakes e Turner, 1986); e (3) pelos fatores que são associados à formação psicossocial do grupo. O conjunto desses fatores (interações interpessoais, similaridade, proximidade, objetivos partilhados, história em comum, entre outros) pode afetar a abrangência da identificação dos indivíduos com o grupo (Ashforth e Mael, 1989) e com o líder.

De fato, o autoconceito é constantemente afetado pelos processos de identificação que são desenvolvidos pelo indivíduo até que ele atinja certo estágio de autonomia. Esse processo é interminável e o indivíduo se espelha continuamente em outras pessoas, a fim de compor sua identidade. Segundo as teorias da psicologia social, a categorização social produz certa despersonalização dos indivíduos (Hogg e Terry, 2000) e por isso gera, segundo Turner (1985) e Turner et al. (1987), o fenômeno da identidade social. Categorização refere-se ao processo pelo qual o eu é assimilado cognitivamente nos protótipos do grupo, despersonalizando seu autoconceito. Despersonalização, por sua vez, refere-se à mudança na autoconceitualização e na base da percepção dos outros (Hogg e Terry, 2000).

Isso significa que a identidade não é fixa e imutável, mas que os processos de identificação podem, de modo geral, ser mais intensos em determinados períodos da vida dos indivíduos ${ }^{(2)}$. Tal intensidade não exclui a multiplicidade de pessoas 
existentes em nós, já que somos o resultado de uma pluralidade de pessoas com as quais fomos e nos vamos identificando ao longo de nossas vidas (Maffesoli, 1998). Nesses termos, a identidade dos indivíduos é uma síntese de múltiplas identificações, que vão ocorrendo em função da vinculação a diferentes grupos sociais, tais como família, escola, trabalho e outras organizações. As possibilidades de identificação são ilimitadas e não há nenhuma âncora que as retenha (Placer, 1998).

Em resumo, pode-se dizer que o processo da identificação está intimamente ligado aos aspectos (Pratt, 1998): (1) de segurança psicológica - a identificação funciona como um mecanismo de cópia que as pessoas utilizam para resolver inconsistências emocionais; (2) de afiliação - a necessidade de o indivíduo se perceber como membro de um grupo, necessidade de agregação, a fim de vencer o isolamento social; (3) de autovalorização - o indivíduo busca imitar o comportamento daquele que ele julga importante para seu engrandecimento, para a construção de um autoconceito positivo; e (4) de significado - o indivíduo busca referências de valores para incorporar ao seu comportamento, como forma de atribuir um propósito à sua vida.

Grosso modo, para se identificar, um indivíduo não precisa despender esforços com os objetivos do grupo, mas sobretudo perceber-se cognitivamente e emocionalmente como integrante do grupo. Dessa forma, afeto e cognição estão presentes na identificação (Ashforth et al., 1998), porque o processo de identificação social é estruturado pela redução da incerteza subjetiva (Hogg e Terry, 2000); enfim, porque requer conhecimento individual de pertencimento a grupos sociais, devendo ter essa filiação algum significado emocional (Tajfel, 1972). Sob essa ótica, identificação é o processo em que consciência e sentimento se equacionam a um só tempo (Miranda, 1998), remetendo-nos à expressão mais remota de uma ligação emocional com outra pessoa, em que os limites do eu não estão completamente definidos (Freud, 1959).

\section{A Dinâmica entre Liderança e Identificação}

As teorias sobre identificação confirmam que não existe papel de líder isoladamente; por isso identificação é uma noção básica para refinar a compreensão do processo de liderança no contexto contemporâneo das organizações. Como a formação do vínculo da identificação sucede no momento em que as ações de uma pessoa vão ao encontro das expectativas da outra, o vínculo da liderança ocorre de maneira fecunda e produtiva quando as ações do líder forem ao encon- 
tro das expectativas do liderado e vice-versa. A identificação ocorre de maneira efetiva quando os comportamentos se caracterizam por expectativas complementares, podendo daí surgir uma situação de simpatia mútua e de reciprocidade no que diz respeito ao alcance de metas estabelecidas.

A reciprocidade desses comportamentos estabelece o elo que fundamenta a dinâmica da influência nas organizações contemporâneas, como apresentamos, a seguir, na Figura 1. De um lado, a liderança se constitui na busca do líder que almeja ser escolhido e que, para se manter influente, opta pela constante reconstrução de si mesmo, mobilizando recursos políticos, cognitivos e emocionais para oferecer e negociar ordenamentos significativos da realidade do grupo. De outro lado, a identificação se consolida no processo de reconhecimento e consentimento da influência de uma pessoa que reduza a incerteza subjetiva, que negocie e confira um significado às atividades cotidianas e que estabeleça um sentimento de afiliação, ou seja, que forneça um substrato emocional, social e cognitivo no qual e com o qual todos se possam reconhecer por meio dos protótipos e categorias que aquela pessoa represente para o grupo. Nitidamente, consentimento e ordenamento movem, de forma continuada, os relacionamentos entre influenciador e influenciados.

\section{Figura 1: A Dinâmica entre Liderança e Identificação}

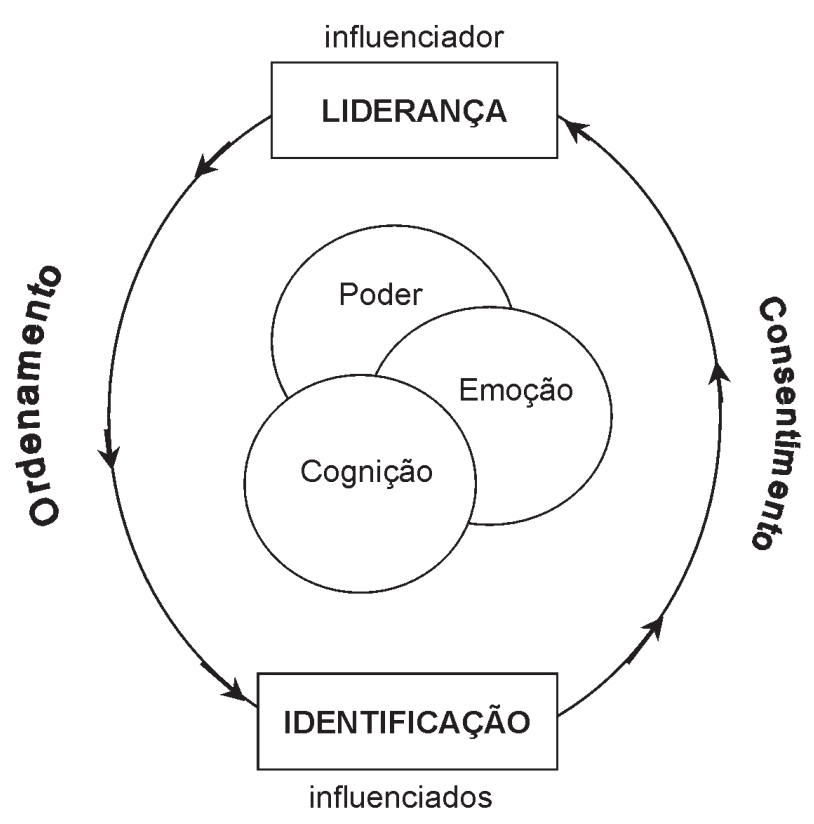


- Cognição, Emoção e Poder. A dinâmica entre liderança e identificação se estabelece no terreno de variados processos. Opera pela interação entre processos políticos, cognitivos e emocionais e gera, simultaneamente, ordenamento significativo da realidade e consentimento por parte dos influenciados. Cognição é uma das dimensões mais explicitamente abordadas pela literatura organizacional, indicando que tanto liderança quanto identificação envolvem processos cognitivos de avaliação e descrição da realidade. Líderes e liderados escolhem, constroem e ordenam cognitivamente suas relações. Esquemas cognitivos fazem parte das interações sociais de influência, pois organizam e estruturam as bases da negociação, do entendimento, da seleção e da avaliação de descrições, situações e atividades oferecidas por líderes e reconhecidamente identificadas e consentidas por seguidores.

De maneira complementar, reconhecimento e influência são permeados pelas emoções. As emoções indicam o grau de valor que as pessoas atribuem às situações no processo de identificação: dizem-nos quão importante é a identificação, refletem o significado emocional da identificação (Harquail, 1998), sugerem e ratificam a forma pela qual as pessoas pensam, se comportam e tomam decisões. Apesar de ser um terreno teórico que começa a ser explorado nos estudos sobre administração e organizações, pesquisadores da problemática adiantam que as emoções desempenham papel central na vida organizacional (Ashforth e Humphrey, 1993, 1995; Fineman, 1996; Thévenet, 1999), especialmente no processo de liderança (Yiannis, 1999; George, 2000).

As emoções são estudadas sob a ótica da perspectiva: (1) neurológica, que atribui aos órgãos dos sentidos a explicação do fenômeno; assim a emoção é o resultado de uma avaliação perceptiva; (2) psicológica, que relaciona os estudos de emoção aos de cognição; e (3) social, que as aborda como frutos de uma construção social. Para esta última perspectiva a cultura exerce papel preponderante na determinação das emoções. Em qualquer dessas dimensões, as emoções configuram-se como expressões dos sentimentos, crenças e desejos dos indivíduos (Taylor apud Griffiths, 1997). Para estudá-las os pesquisadores têm recorrido a categorizações, tais como emoções positivas (por exemplo, felicidade e surpresa) e negativas (por exemplo, medo, tristeza, desprezo e raiva). Bagozzi, Wong e Yi (1999), ao estudarem o papel da cultura e gênero em diferentes sociedades, caracterizaram como emoções positivas o amor (afeição, carinho, afeto) e a alegria (felicidade, prazer, satisfação, apreciação) e como emoções negativas a raiva (hostilidade, irritabilidade, frustração, ódio, aborrecimento), a tristeza (depressão, desagrado), o medo (ansiedade, preocupação, nervosismo, susto) e a culpa (remorso, vergonha, embaraço). Gross (1999) discorre sobre o controle das emoções, especialmente das emoções negativas, tais como a ansiedade, a descompostura, ou a agressividade, que podem configurar-se como barreiras para a socialização dos indivíduos nas organizações. 
Autores como Harquail (1998) e Schwarz (2000) têm apontado a correlação existente entre as emoções e o processo de escolhas por parte dos indivíduos, afirmando que indivíduos com bom humor tendem a superestimar avaliações positivas e subestimar avaliações negativas em diferentes circunstâncias. É por essa razão que o fenômeno da liderança é também produzido a partir da construção de efeitos especiais, capazes de atingir os órgãos dos sentidos dos indivíduos e assim produzir uma emoção, indispensável para dar força à identificação. Dessa forma, os líderes são reconhecidos e ordenam a realidade subjetiva das situações e atividades organizacionais, porque suas visões são influenciadas por um teatro interior vivenciado e carregado emocionalmente (Lapierre, 1991, 1995; Kets de Vries, 1997). Eles tendem a desenvolver certa sensibilidade às emoções de seus subordinados, a fim de favorecer e manter um tipo de ambiente no qual as pessoas tenham experiências significativas. Assim agindo, as pessoas se identificam por intermédio de muitos símbolos e imagens que evocam memórias, valores e crenças historicamente experimentados e emocionalmente vividos e lembrados. As emoções, além de se caracterizarem por estados alternados de diferente intensidade, misturam-se também com o passado e com o futuro dos indivíduos.

Ainda assim, emoção e cognição não são processos lineares e certamente, no contexto da dinâmica entre liderança e identificação, interagem com os aspectos políticos. Emoção e cognição estão intrinsecamente ligadas, porque o estado emocional atua com primazia sobre os processos cognitivos; entretanto liderança e identificação também incluem manifestações de poder nas organizações. Tais processos refletem e afetam valores e interesses, gerando e estabelecendo interdependências e desigualdades de influência. Poder e cognição, por sua vez, refletem experiências passadas e presentes e, em seu conjunto, fornecem expressão emotiva para as pessoas. Como alerta Yiannis (1999), é necessário não reduzir relações políticas a relações interpessoais, porque as estruturas do controle político e organizacional permeiam as dinâmicas mentais e emocionais, sem, é claro, se limitarem a elas.

"Os diferentes aspectos do poder nos remetem às raízes das preocupações humanas: a força e a fraqueza, a dominação e a dependência, o controle e a submissão. A vontade de um se exerce em detrimento da vontade do outro. Esses diferentes aspectos perturbam e repelem" (Kets de Vries, 1995), fazendo parte do processo de identificação. Nesses termos, a liderança é uma atividade intrinsecamente política, à medida que, ao ordenar simbolicamente atividades e relações e suscitar reconhecimento, tende a excluir algumas atividades e relações em detrimento de outras e a legitimar alguns interesses em detrimento de outros. Atores organizacionais interagem interdependentemente em relação a diferentes avaliações de seus contextos e atividades. Dependendo da participação e do posicionamento no jogo político, essas diferenças incluem ou excluem 
diferentes construções de interesses e comprometimentos que convivem com uma maior ou menor adesão às imagens projetadas e identificadas de ordenamento substantivo da realidade. Evidentemente, nesse processo de ordenamento, alguns serão mais hábeis em criar e mobilizar recursos simbólicos e materiais para proteger e promover seus valores e interesses particulares.

Atores organizacionais envolvidos no processo de influência, inserem-se simultaneamente nos "jogos de poder" (Frost, 1987) e utilizam mecanismos para estruturar e regular suas relações de poder - às vezes colaborando, às vezes competindo - dependendo de seus posicionamentos com relação às contingências $\mathrm{e}$ dependências estratégicas e ao acesso de que dispõem a recursos materiais e simbólicos. Relações de poder indicam que a liderança é eminentemente precária (Knights e Willmott, 1992), podendo reverter ou alterar a qualquer instante a base cognitiva e emotiva construída pela identificação. Além disso, vale ressaltar que relações de poder estão profundamente enraizadas em pressupostos culturais, emocionais e cognitivos sobre a forma apropriada de estruturação das relações entre as pessoas (Biggart e Hamilton, 1987). Sob essa perspectiva política, a identificação se torna uma ligação frágil, na qual a projeção pode tomar novos rumos a qualquer momento, dependendo de como os interesses pessoais e coletivos são articulados no decorrer das relações de influência.

Ordenamento e Consentimento. O esquema conceitual proposto, que articula cognição, emoção e poder, é dinamizado pelos fenômenos de ordenamento e consentimento. Ordenamento se refere ao processo pelo qual o líder percebe que o mundo exterior não tem sentido imediato para as pessoas e que o ordenamento significativo de suas experiências emocionais pode conferir força e convicção à sua influência; entretanto, reciprocamente, esta influência se verifica efetivamente, quando suas crenças, valores e atitudes vão encontrando reconhecimento nas pessoas e ressonância com o imaginário da organização e do grupo, com suas esperanças, angústias e desejos latentes ou manifestos partilhados por todos (Aubert, 1991; Kets de Vries, 1991). Para que esse fenômeno ocorra, no entanto, é necessário que exista um processo de identificação com a figura do líder, um processo de captura da sua imagem.

De fato, para que a liderança ocorra, a imagem do líder é destacada, alicerçada em qualidades diferenciadas e atraentes, a fim de poder despertar no outro o desejo de seguir o líder. A diferença e o ordenamento significativos da realidade, conforme sejam propostos, é que distinguem o líder de seus pares e, ao mesmo tempo, produzem nos seguidores o desejo de segui-lo e de se deixarem influenciar por ele; por isso o líder deve ter a capacidade de criar-se a si próprio para se tornar diferente a todo momento, já que, à medida que os outros o seguem, ele vai deixando de ser diferente (Bennis, 1999). Ao reinventar a si mesmo, ele rompe 
com o seu passado, negando valores anteriores para produzir uma nova autoimagem que acompanhe as mudanças na vida relacional do grupo.

Nesses termos, os seguidores podem sentir-se revitalizados, à medida que o seu eu se funde na identificação com o líder e que eles interagem cognitivamente, emocionalmente e politicamente com uma realidade psicossocial que lhes é oferecida e reconhecida como significativa. A identificação pode tornar-se uma espécie de captura conflituosa, mas também revigorante porque, pela identificação, o seguidor participa simbolicamente do poder do líder. Aquele que se identifica talvez creia que está capturando o outro, mas é ele que pode estar sendo capturado (Mannoni apud Signorini, 1998) por um processo de despersonalização e pela nova categorização social tipificada e exigida pelo grupo.

\section{Implicaçóes para a Prática e Pesquisa Organizacional}

O esquema conceitual proposto neste artigo destaca, no mínimo, três tipos de implicações para o estudo da liderança. Primeiro, porque considerar a liderança como fenômeno processual fundamentalmente psicossocial que requer interação e relacionamento, proporciona uma forma de repensá-la e de adequá-la às mudanças organizacionais contemporâneas. As relações de influência e de identificação desempenham papel fundamental, à medida que as organizações e o discurso gerencial difundem cada vez mais a necessidade de trabalhar em equipe, de cooperar e de inovar continuamente no desenvolvimento de projetos, serviços e produtos. Tais relações se tornam cada vez mais centrais, para refinar a compreensão dos processos de influência entre atores organizacionais, que convivem num contexto sobrecarregado de imagens e pseudo-eventos (Alvesson, 1990), de reestruturações e adaptações.

Segundo, porque, inserta neste panorama de mudanças e atrelada à identificação que encontrará, a liderança tende a se tornar uma dinâmica circunstancial e situacional, em que líderes e liderados ocupam posições suscetíveis de intercâmbio. A liderança envolve um processo de ordenamento significativo da realidade de um grupo. Líderes desenvolvem, implementam, negociam e renegociam esquemas cognitivos, emocionais e políticos que definem e cristalizam as situações cotidianas de trabalho; entretanto essa oferta de ordenamento se torna efetiva somente quando adquire reconhecimento e consentimento por parte dos membros do grupo, ou seja, o ordenamento dos significados afeta o ordenamento significativo das atividades e relações no momento em que promove e mobiliza valores, conhecimentos, sentimentos, mas também interesses que são represen- 
tativos para as pessoas. O estudo da liderança ganha novas possibilidades de aprofundamento, quando leva em conta o processo político, cognitivo e emocional pelo qual a ordem social é negociada e praticada, promovendo e protegendo valores e interesses específicos (Hosking, 1988).

Terceiro, porque, ao reconhecer que todos os atores são participantes ativos no desenrolar das ações e relações cotidianas de trabalho, essa dinâmica tende a (1) suscitar postura de cooperação e comprometimento e (2) a favorecer a transformação, inovação e renovação de processos, estruturas e atividades organizacionais. De fato, abordar o papel fundamental do processo de identificação no exercício da liderança nos leva a conceber os focos de força e fraqueza dos indivíduos como difusos, podendo produzir em todos os envolvidos uma sensação de plenitude, derivada da convergência de necessidades e de sentimentos. A partir do momento em que se concebem subordinados não mais se comportando de forma passiva ou como vítimas da ação indiscutível do líder, é que se pode favorecer uma melhor compreensão da dimensão abrangente e relacional da atividade do líder como administrador do sentido, como ator social integrador e, conseqüentemente, como agente de mudança e inovação nas organizações. Fenômenos tais como comprometimento, cooperação, engajamento e inovação organizacionais dependem do relacionamento próximo e sensível entre líderes e seguidores, mutuamente baseados em uma ressonância com a distinção, o prestígio e a saliência dos valores e práticas adotados e negociados pelo grupo. Quando a identificação com um grupo e com o líder se torna saliente, aumenta a motivação para atingir objetivos, melhoram o tratamento e a interação dos membros do grupo, contribuindo para comportamentos com predomínio da ajuda mútua e cooperação (Scott e Lane, 2000).

Repensar o processo de liderança sob a ótica da identificação traz implicações também para a prática organizacional. Para serem bem sucedidos no desempenho da sua influência, os indivíduos devem desenvolver certa competência e sensibilidade. $O$ fato de a liderança contemporânea se desenrolar cada vez mais no âmbito do relacionamento freqüente e face a face, suscita a percepção dos indivíduos para atividades e relações de influência mais sutis, que envolvem conhecimento e sentimento, mas também poder. Dessa forma, aqueles que exercem influência passam pelo desafio de se tornarem mais sensíveis para combinar ação, reflexão e emoção. Os líderes devem encontrar satisfação e realização não só na aquisição e na mobilização de recursos de poder e controle para alcançar metas estabelecidas e sonhadas (Northouse, 1997). Devem também conhecer bastante sobre si próprios para perceber as vicissitudes das relações de poder e de influência e ser reconhecidos, lembrados e exaltados com respeito e afeto. De fato, aqueles que se encontrarem em posição de influência devem desenvolver sensibilidades políticas, emocionais e cognitivas para serem capazes 
de oferecer um enquadramento substantivo da realidade cotidiana das pessoas e gerenciar as ambigüidades do poder, podendo, nesse processo, indicar vias para uma vida coletiva criativa, produtiva (Kets de Vries, 1995) e inovadora.

\section{Conclusões}

Neste artigo, por intermédio da noção de identificação, exploramos a liderança nas organizações contemporâneas como processo psicossocial, baseado no relacionamento entre líder e seguidores, que envolve e articula cognição, emoção, poder, consentimento e ordenamento. Os processos de influência nas organizações resultam das interações dos indivíduos em que, por um lado, influenciadores estruturam e ordenam os significados das atividades, visões e relações entre as pessoas; entretanto, por outro lado, essa influência é consentida, quando encontra respaldo, reconhecimento e identificação no âmbito dos processos cognitivos, emocionais e políticos vivenciados e praticados pelos membros do grupo regularmente. Assim, constatamos que tal complementaridade entre a liderança e a identificação se caracteriza pela relação simbiótica, derivada do encontro das necessidades e desejos, sentimentos e interesses dos indivíduos. O entendimento do processo de influência nas organizações contemporâneas envolve, então, um enfoque da liderança sob a ótica do consentimento, da reciprocidade e da complementaridade de comportamentos entre indivíduos, liderança essa que ocorre por meio da identificação. Tal abordagem nos levou a ressaltar os aspectos circunstanciais e situacionais da liderança e a constatar que, quanto mais tênues e sensíveis os limites entre a força da identificação e a da liderança, maior será a intensidade do relacionamento, podendo resultar não só na renovação de processos políticos, cognitivos e afetivos, como também na constituição de novas identidades coletivas e de novos parâmetros para se criar, produzir e inovar em contexto organizacional.

\section{NOtAS}

${ }^{1}$ As novas abordagens sobre a liderança descrevem e categorizam uma série de perspectivas que surgiram no decorrer da década de 80 (Bryman, 1992). É empregada uma terminologia diversa para caracterizar essas novas abordagens: liderança transformadora (Bass, 1985), liderança carismática (Conger, 1989), liderança visionária (Sashkin, 1988; Westley e Mintzberg, 1989), entre outras.

${ }^{2}$ Por exemplo, Erikson (1980) aponta o fato de que existe certa predisposição mais intensa em indivíduos para desenvolver processos de identificação durante determinadas fases do ciclo de suas vidas. Seria na fase da juventude e da adolescência que "o perder e encontrar-se no outro" assumiria 
maior significado nas relações psicossociais, coincidindo com maior necessidade de identificar-se com grupos e pares.

\section{ReferênCias Bibliográficas}

\section{ALVESSON, M.}

Organization: from substance to image. Organization Studies, v. 11, n. 3, p. 373-394, 1990.

Leadership as social integrative action - a study of a computer consultancy company. Organization Studies, v. 13, n. 2, p. 185-209, 1992.

Management of knowledgeintensive companies. New York: Walter de Gruyter, 1995a.

Leadership studies: from procedure and abstraction to reflexivity and situation. Working Paper Series, Institute of Economic Research, Department of Business Administration, Lund University, 1995 b.

ASHFORTH, B. E. et al.

Identification with organizations. In: WHETTEN, D.; GODFREY, P. C. Identity in organizations. London: Sage Publications, 1998.
ASHFORTH, B. E.; HUMPHREY, R. H.

Emotional labor in service roles: the influence of identity. Academy of Management Review, v. 16, n. 1, p. 88-115, 1993.

Emotion in the workplace: a reappraisal. Human Relations, v. 48, n. 2, p. 97-125, 1995.

ASHFORTH, B. E.;

MAEL, F.

Social identity theory and the organization. Academy of Management Review, v. 14, p. 20-39, 1989.

AUBERT, N.

Leadership. In: AUBERT, N. et al. Management: aspects humains et organisationnels. Paris: Presses Universitaires de France, 1991. 
BAGOZZI, R.;

WONG, N.;

YI, Y.

The role of culture and gender in the relationship between positive and negative affect. Cognition and Emotion, v. 13, n. 6, p. 641$672,1999$.

BASS, B.

Leadership and performance: beyond expectations. New York: Free Press, 1985.

BAUDRILLARD, J.;

GUILLAUME, M.

Figures de l'altérité. Paris: Descartes \& Cie., 1994.

BENNIS, W.

Managing people is like herding cats. Provo: Executive Excellence Publishing, 1999.

BERGAMINI, C. W.

Liderança: administração do sentido. São Paulo: Atlas, 1994.

BIGGART, N. W.;

HAMILTON, G. C.

An institutional theory of leadership. Journal of Applied Behavioral Science, v. 23, n. 4, p. 429-741, 1987.
BRYMAN, A.

Charisma and leadership of organizations. London: Sage Publications, 1992.

Leadership in organizations. In: CLEGG, S. R.; HARDY, C.; NORD, W. R. Handbook of organization studies. London: Sage Publications, 1996.

CONGER, J. A.

The charismatic leader: behind the mystique of exceptional leadership. San Francisco: Jossey-Bass, 1989.

CZARNIAWSKA-JOERGES, B.;

WOLFF, R.

Leaders, managers, entrepreneurs on and off the organizational stage. Organization Studies, v. 12, n. 4, p. 529-546, 1991.

DAVEL, E.;

ROLLAND, D.;

TREMBLAY, D.-G.

A nova distribuição de responsabilidades na organização do trabalho em equipe em Quebec. In: III CONGRESO LATINOAMERICANO DE SOCIOLOGÍA DEL TRABAJO (2000: Buenos Aires). Anales... Buenos Aires, 2000. 
ERICKSON, E. H.

Identity and the life cycle. New York: W. W. Norton \& Company, 1980.

FINEMAN, S.

Emotion and organizing. In: CLEGG, S. R.; HARDY, C.; NORD, W. R. (Eds.). Handbook of organization studies. London: Sage Publications, 1996.

FREUD, S.

Group psychology and the analysis of the ego. New York: Norton, 1959.

FROST, P. J.

Power, politics, and influence. In: JABLIN, F. M. et al. Handbook of organizational communication an interdisciplinary perspective. London: Sage Publications, 1987.

GEORGE, J. M.

Emotions and leadership: the role of emotional intelligence. Human Relations, v. 53, n. 8, p.1027$1055,2000$.

GRIFFITHS, P. E.

What emotions really are: the problem of psychological categories. Chicago: The University of Chicago Press, 1997.

\section{GROSS, J.}

Emotion regulation: past, present, future. Cognition and Emotion, v. 13, n. 5 , p. 551-573, 1999.

HARQUAIL, C. V.

Organizational identification and the 'whole person': integrating affect, behavior, and cognition. In: WHETTEN, D.; GODFREY, P. $C$. Identity in organizations. London: Sage Publications, 1998.

HIRSCHHORN, L.

Reworking authority: leading and following in the post-modern organization. Massachusetts: The MIT Press, 1977.

HOGG, M.;

TERRY, D.

Social identity and selfcategorization processes in organizational context. Academy of Management Review, v. 25, n. 1, p. 121-140, 2000.

HOLLANDER, E. P.

Leadership dynamics: a practical guide to effective relationships. New York: Free Press, 1978.

HOSKING, D.-M.

Organizing, leadership and skilful process. Journal of Management Studies, v. 25, n. 2, p. 147-166, 1988. 
HOSKING, D.-M.;

FINEMAN, S.

Organizing processes. Journal of Management Studies, v. 27, n. 6, p. 583-604, 1990.

HUNT, J. G. et al.

Emerging leadership vistas. Massachusetts: Lexington Books, 1988.

\section{KETS DE VRIES, M. F.}

Whatever happened to the philosopher-king? The leader addiction to power. Journal of Management Studies, v. 28, n. 4, p. 339-5, 1991.

Leaders, fous et imposteurs. Paris: Éditions Eska, 1995.

Liderança na empresa. São Paulo: Atlas, 1997.

KNIGHTS, D.;

WILLMOTT, $\mathrm{H}$.

Conceptualizing leadership processes: a study of senior managers in a financial services company. Journal of Management Studies, v. 29, n. 6, p. 761-782, 1992.
LAPIERRE, L.

Exploring the dynamics of leadership. In: KETS DE VRIES, M. F. R. Organizations on the couch: clinical perspectives on organizational behavior and change. San Francisco: JosseyBass, 1991.

Imaginário e liderança. São Paulo: Atlas, 1995.

MAFFESOLI, M.

O tempo das tribos. São Paulo: Forense Universitária, 1998.

MIRANDA, C. L. S.

Identidade síntese das múltiplas identificações. São Paulo: Cabral Editora Universitária, 1998.

NORTHOUSE, P. G.

Leadership: theory and practice. London: Sage Publications, 1997.

OAKES, P. J.;

TURNER, J. C.

Distinctiveness and the salience of social category membership: is there an automatic perceptual bias toward novelty? European Journal of Social Psychology, v. 16, p. 325-344, 1986. 
PFEFFER, J.

Management as symbolic action: the creation and maintenance of organizational paradigms. Research in Organizational Behavior, v. 3, p. 1-52, 1981.

PLACER, F. G.

Identidade, diferença e indeferência: o si mesmo como obstáculo. In: LARROSA, J.; LARA, N. P. (Orgs.). Imagens do outro. Petrópolis: Vozes, 1998.

PRATT, M. G.

To be or not to be? Central questions in organizational identification. In: WHETTEN, D.; GODFREY, P. C. Identity in organizations. London: Sage Publications, 1998.

RICOEUR, P.

O si-mesmo como um outro. São Paulo: Papirus, 1990.

\section{SASHKIN, M.}

The visionary leader. In: CONGER, J. A.; KANUNGO, R. N. (Eds.). Charismatic leadership: the elusive factor in organizational efectiveness. San Francisco: Jossey-Bass, 1988.

SCHWARZ, N.

Emotion, cognition and decision making. Cognition and Emotion, v. 14, n. 4, p. 433-440, 2000.
SCOTT, S.;

LANE, $\mathrm{V}$.

A stakeholder approach to organizational identity. Academy of Management Review, v. 25, n. 1, p. 43-62, 2000.

SELZNICK, P.

Leadership in administration. New York: Harper and Row, 1957.

SENNETT, R.

The corrosion of character: the personal consequences of work in the new capitalism. New York: Norton, 1998.

SIGNORINI, I.

Língua(gem) e identidade. Campinas: FAPESP, 1998.

SMIRCICH, L.;

MORGAN, G.

Leadership: the management of meaning. The Journal of Applied Behavioral Science, v. 18, n. 3, p. 257-273, 1982.

SMITH, P. B.;

PETERSON, M. F.

Leadership, organizations and culture. London: Sage Publications, 1989. 
TAJFEL, H.

La catégorisation sociale. In: MOSCOVICI, S. Introduction à la psychologie sociale. Paris: Larousse, 1972. v. 1.

\section{THÉVENET, M.}

Le travail: que d'émotions! Revue Française de Gestion, [s.n.], p. 140-152, 1999.

TRICE, H. M.;

BEYER, J. M.

Cultural leadership in organizations. In: THE $4^{\mathrm{TH}}$ I N T E R N A T I O N A L CONFERENCE ON O R G A N I Z A T I O N A L SYMBOLISM AND CORPORATE CULTURE. (1989: Fontainebleau). Proceedings... Fontainebleau, 1989.

TURNER, J. C.

Social categorization and the self-concept: a social cognitive theory of group behavior. In: LAWLER, E. J. (Ed.). Advances in group processes: theory and research. Greenwich: JAI Press, 1985. v. 2.
TURNER, J. C. et al.

Rediscovering the social group: a self-categorization theory. Oxford: Blackwell, 1987.

WESTLEY, F. R.;

MINTZBERG, $\mathrm{H}$.

Visionary leadership and strategic management. Strategic Management Journal, v. 10, p. 17-32, 1989.

YIANNIS, G.

Organizations in depth. London: Sage Publications, 1999.

YUKL, G.

Managerial leadership: a review of theory and research. Journal of Management, v. 15, n. 2, p. 251-289, 1989.

YUKL, G.;

VAN FLEET, D.

Theory and research on leadership in organizations. In: DUNNETTE, M. D.; HOUGH, L. M. (Eds.). Handbook of industrial and organizational psychology. Palo Alto: Consulting Psychologists Press, 1992. 